\title{
Pendampingan Sistem Monitoring Absensi dan Pelanggaran Siswa Berbasis Web dan Bot Telegram
} Mochammad Faid ${ }^{1}$, Mohammad Sa'id ${ }^{2}$, Basori Alwi ${ }^{3}$, Shelly Oktavianti ${ }^{4}$, Muhammad Supyan ${ }^{5}$

Universitas Nurul Jadid, Probolinggo 1, 2, 3, 4, 5

\{mfaid@unuja.ac.id ${ }^{1}$, Syaid37911@gmail.com², basoriulum123@gmail.com³, shely.oktavianti23@gmail.com ${ }^{4}$,muhammadsupyan0207@gmail.com5

\begin{tabular}{ll} 
Submission: 2021-04-14 Received: 2021-04-29 Published: 2021-04-30 \\
\hline $\begin{array}{l}\text { Keywords: } \\
\text { Mentoring, }\end{array}$ & Abstract. The purpose of this web-based student attendance and \\
Educational & is to make it easier for schools and student guardians to monitor \\
Institutions, & disciplinary and student violation levels, so that the school can use \\
Discipline, & it in this case SMP Nurul Jadid as evaluation material and \\
Telegram Bot, & consideration for making an Existing policies and regulations at \\
Web-Based & Nurul Jadid Middle School, Telegram Bot are functioned to attend \\
Applications & students by the teacher, so that the results of teacher input will be \\
& immediately recapitulated by the system, while for the website it is \\
& made using the Codelgniter Framework to facilitate recording \\
& related attendance and student violations, while the mentoring \\
process is carried out to the discipline and student affairs \\
department so that later it will be disseminated to all teachers at \\
Nurul Jadid Middle School.
\end{tabular}

Katakunci: Pendampingan, Lembaga Pendidikan, Kedisplinan, Bot Telegram, Aplikasi Berbasis Web

\begin{abstract}
Abstrak. Tujuan pendampingan sistem informasi absensi dan pelanggaran siswa berbasis web dan bot telegram ini adalah untuk memudahkan pihak sekolah dan wali murid dalam memonitoring kedispilanan dan level pelanggaran siswa, sehingga bisa digunakan pihak sekolah dalam hal ini SMP Nurul Jadid sebagai bahan evaluasi dan bahan pertimbangan untuk membuat sebuah kebijakan dan peraturan yang ada pada SMP Nurul Jadid, Bot Telegram ini di fungsikan untuk mengabsen siswa-siswi yang dilakukan oleh Guru, sehingga hasil input guru akan langsung direkap oleh sistem, sedangkan untuk Website dibuat menggunakan Framework Codelgniter untuk memudahkan perekapan terkait absensi dan pelanggaran siswa, adapun proses pendampingannya dilakukan kepada bagian kedisplinan dan kesiswaan agar nanti disosialisasikan kepada semua guru yang ada pada SMP Nurul Jadid.
\end{abstract}

\section{Pendahuluan}

Lembaga pendidikan merupakan wadah yang bertujuan untuk membimbing manusia untuk menjadi lebih baik. semua orang yang ada pada 
institusi tertentu akan mengalami perubahan yang signifikan sesuai dengan karakteristik dari lembaga atau institusi. Menurut K.H. Dewantara lembaga pendidikan terpusat pada 3 bagian diantaranya keluarga, sekolah dan masyarakat, sedangkan menurut undang-undang Sisdiknas pada tahun 2003 NO.20 lembaga pendidikan yang dimaksud adalah lembaga Formal, non formal, dan informal (Marlina Gazali,2013).

Tidak dapat dipungkiri bahwa lembaga keluarga, sekolah dan masyarakat mempunyai peran yang sangat penting sehingga mampu menjadi tempat latihan siswa untuk mengembangkan dan menumbuhkan potensinya sebagai makhluk yang mandiri, berjiwa sosial, serta religius.

Pendidikan harusnya dapat mensuport dan memotivasi keaktifan siswa, karena siswa memiliki hak untuk dihormati oleh semua pemangku kewajiban, seperti orang tua, guru, dan civitas akademik lainnya, Hak siswa adalah keharusan sehingga siswa bisa berkembang dan tumbuh secara humanis sejalan dengan perkembangan kejiwaan dari masing-masing siswa.

Dengan memaksimalkan peran dari ketiga lembaga pendidikan tersebut sehingga dapat dipastikan akan banyak melahirkan siswa bangsa yang cerdas dan berakhlak.

Faktor yang dapat mensport kualitas siswa yang bermutu diantaranya adalah kerajinan, sarana yang mendukung, serta pendidik yang profesional. dalam hal menciptakan tenaga pendidik yang profesional kemendikbud memberikan beasiswa 1 bagi guru dan SMP. di indonesia jumlah guru SD baik yang negri atau swasta berkisar kurang lebih mencapai 1850 guru. dari jumlah tersebut $60 \%$ sudah lolos kualifikasi sebagai tanaga pendidik profesional. setiap tahunnya kemendikbud memberikan jata 100 ribu kepada guru untuk meningkatkan kualitasnya dengan memberi pertolongan program beasiswa s1 bagi guru SD dan SMP (Kamil Malik,2016).

Sekolah Menengah Pertama (SMP) Nurul Jadid adalah salah satu unit pendidikan tertua di bawah naungan pondok pesantren Nurul Jadid Paiton Probolinggo yang didirikan langsung oleh pendiri Peantren Nurul Jadid Kiai Zaini Mun'im pada tahun 1950. Bermula ketika dalam perjalanan pulang dari menjenguk putranya di Pesantren Darul Ulum Jombang, Kiai Zaini sangat prihatin melihat banyak pelajar umum (SMP/SMA) berpakaian olah raga, bergaul campur-baur, mengabaikan nilai-nilai ahlakul karimah.

Sepulang dari Jombang beliau berdiskusi panjang, dengan pengurus pesantren untuk menyelamatkan generasi muda umat Islam dengan 
mendirikan pendidikan umum di pesantren, suatu inisiatif yang berani mengingat pada masa itu kehadiran pendidikan umum masih dianggap oleh sebagian ummat Islam sebagai "warisan" kolonial Belanda. Tetapi, Kiai Zaini mengambil keputusan tegas dengan bertekat mendirikan pendidikan umum.

Setelah melalui pertimbangan panjang, maka pada 1 januari tahun 1970 berdirilah SMP Nurul Jadid. Pada awal berdirinya, hanya 29 siswa baru yang menempati ruang yag sangat sederhana. Pada tahun 1973, berdasarkan penetapan Kanwil Pendidikan dan Kebudayaan Provinsi Jawa Timur Kabin PMUP No.706/KP/73, Sekolah Menengah Pertama Nurul Jadid (SMPNJ) dinyatakan telah masuk dalam lingkungan Pembinaan Sekolah Menengah Pertama Negeri (SMPN) Kraksaan yang berhak melaksanakan ujian negara. Jumlah muridnya pun bertambah menjadi 104 siswa, dari http://smpnj.sch.id/Tentang/sejarah.

Pada tanggal 29 Januari 1996, SMP Nurul Jadid mampu memperoleh status disamakan dari Depdiknas dengan nomor piagam; 625/I.04/1/96/SK. Pada tahun 2005, SMP Nurul Jadid memperoleh predikat TERAKREDITASI- A (sampai sekarang), dan pada tahun 2008 berhasil terpilih menjadi Sekolah Rintisan Standart Nasional (SSN), dari http://smpnj.sch.id/Tentang/profil.

Dalam hal menjaga kualitas siswa-siswinya pihak SMP Nurul Jadid membuat struktur kepengurusan, salah satu struktural kepengurusan yang ada di SMP Nurul Jadid adalah bagian kedisplinan yang merekap data pelanggaran siswa. Pelanggaran siswa memiliki beberapa kategori yang tiap kategorinya memiliki level mulai dari pelanggaran ringan, pelanggaran sedang, dan pelanggaran berat. Bagian struktural kepengurusan lain adalah bagian kesiswaan yang salah tugasnya adalah merekap absensi siswa, dari data yang dikumpulkan oleh bagian kedisplinan dan kesiswaan akan sangat penting bagi pihak sekolah untuk merumuskan kebijakan kebijakan atau peraturan yang bisa menpertahan mutu atau bahkan meningkatkan mutu dari siswa-siswinya.

Namun kendala di lapangan yang ada terkait pengumpulan data baik itu pada bagian kedisplinan dan kesiswaan adalah jumlah siswa-siswinya yang sudah mencapai ribuan, yang semua direkap menggunakan Microsoft excel, hal ini rawan terjadi kesalahan kesalahan terkait teknis dan juga membutuhkan waktu yang tidak sedikit, untuk mengefisienkan waktu yang ada solusi yang paling tepat adalah membangun system yang 
terkomputerasis yang terintegrasi secara online dengan memanfaatkan internet sekolah.

Adapun system yang dibangun smp nurul jadid ini menggunakan sebuah system aplikasi berbasis website yang terintegrasi dengan bot telegram dengan desain model pengembangan sistemnya menggunakan prototyping, dengan menggunakan bot telegram yang memanfaatkan api telegram yang disediakan secara gratis oleh telegram, dapat di manfaatkan sebagai fasilitas untuk menginput absen siswa dan pelanggaran siswa yang mana datanya akan langsung direkap oleh system di aplikasi berbasis web.

Untuk mengawal pertama agar system ini dapat berjalan dengan baik maka perlu pendampingan terhadap bagian kedisplinan dan kesiswaan, Tujuan pendampingan sistem informasi absensi dan pelanggaran siswa berbasis web dan bot telegram ini adalah untuk memudahkan pihak sekolah dan wali murid dalam memonitoring kedispilanan dan level pelanggaran siswa, sehingga bisa digunakan pihak sekolah dalam hal ini SMP Nurul Jadid sebagai bahan evaluasi dan bahan pertimbangan untuk membuat sebuah kebijakan dan peraturan yang ada pada SMP Nurul Jadid, Bot Telegram ini di fungsikan untuk mengabsen siswa-siswi yang dilakukan oleh Guru.

Hasil dari pendampingan ini adalah membuat bagian kedisplinan dan kesiswaan paham akan sistem yang akan dibangun,setelah program dibuat oleh mahasiswa KKN maka diujicoba oleh bagian kedisplinan dan kesiswaan, metode pengembangan sistem yang digunakan adalah metode prototyping, karena di dalam prototyping aplikasi akan terus direvisi sesuai dengan kebutuhan di lapangan.

\section{Metode}

a. Metode Pengumpulan Data

Adapun Cara untuk mengumpulkan data pada penelitian ini dilakukan dengan beberapa cara diantaranya (Fathorazi,2020) adalah sebagai berikut:

1) Observasi

Observasi merupakan kegiatan yang mempunyai tujuan untuk mengetahui, mengerti dan memahami suatu ide, gagasan atau pengetahuan yang telah ada dan terlaksana sebelumnya. Dalam penelitian ini observasi 
dilakukan secara langsung ke objek penelitian yaitu kepada pihak SMP Nurul Jadid tepatnya pada bagian kedisplinan dan kesiswaan.

\section{2) Wawancara}

Wawancara merupakan salah satu cara untuk mendapatkan data yang nantinya akan diolah menjadi sebuah informasi, wawancara dilakukan dengan melakukan pertemua dengan subjek adapun metode yang digunakan dalam wawancara adalah menggunakan metode tanya jawab secara langsung kepada bagian kedisplinan dan kesiswaan pada SMP Nurul Jadid.

\section{3) Dokumentasi}

Teknik pengumpulan data menggunakan dokumen yang dijadikan sebagai sumber dalam menggali data ialah dokumen pribadi untuk.

\section{b. Metode Pengembangan Sistem}

Prototyping merupakan metode pengembangan perangat lunak, yang berupa model fisik kerja system dan berfungsi sebagai versi awal dari sistem. Dengan metode prototyping ini akan dihasilkan prototype sistem sebagai perantara pengembang dan pengguna agar dapat berinteraksi dalam proses kegiatan pengembangan sistem informasi. Agar proses pembuatan prototype ini berhasil dengan baik adalah dengan mendefinisikan aturan-aturan pada tahap awal, yaitu pengembang dan penguna harus satu pemahaman bahwa prototype dibangun untuk mendefinisikan kebutuhan awal. Prototype akan dihilangkan atau ditambahkan pada bagiannya sehingga sesuai dengan perencanaan dan analisis yang dilakukan oleh pengembang sampai dengan ujicoba dilakukan secara simultan seiiring dengan proses pengembangan (Dwi Purnomo, 2017).

Terdapat tiga pendekatan utama prototyping, yaitu:

1) Throw-Away

Prototype dibuat dan dites. Pengalaman yang diperoleh dari pembuatan prototype digunakan untuk membuat produk akhir (final), kemudian prototype tersebut dibuang (tak dipakai).

2) Incremental

Produk finalnya dibuat sebagai komponen-komponen yang terpisah. Desain produk finalnya secara keseluruhan haya ada satu tetapi dibagi dalam komonen-komponen lebih kecil yang terpisah (independent).

3) Evolutionary 
Pada metode ini, prototipenya tidak dibuang tetapi digunakan untuk iterasi desain berikutnya. Dalam hal ini, sistem atau produk yang sebenarnya dipandang sebagai evolusi dari versi awal yang sangat terbatas menuju produk final atau produk akhir.

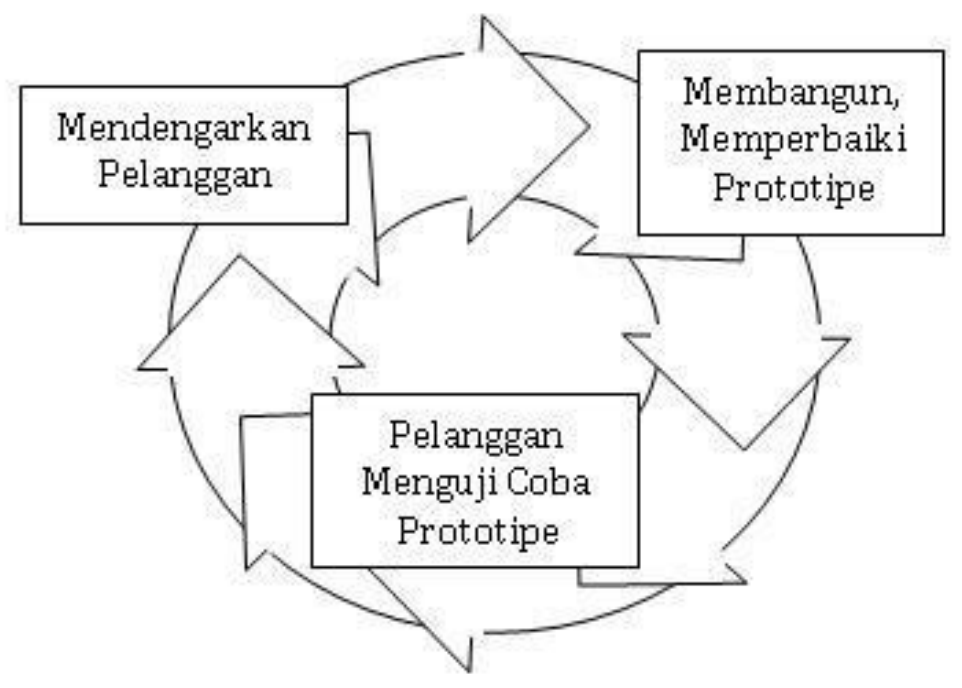

Gambar 1. Model Prototype

\section{Hasil dan Pembahasan}

Model Pengembangan Sistem yang digunakan dalam penelitian ini menggunakan model protype di mana kegiatan-kegiatan yang ada di dalam prototype diantaranya mendengarkan pelanggan, membangun dan memperbaiki sistem, kemudian mengujicobakan kepada pelanggan. 


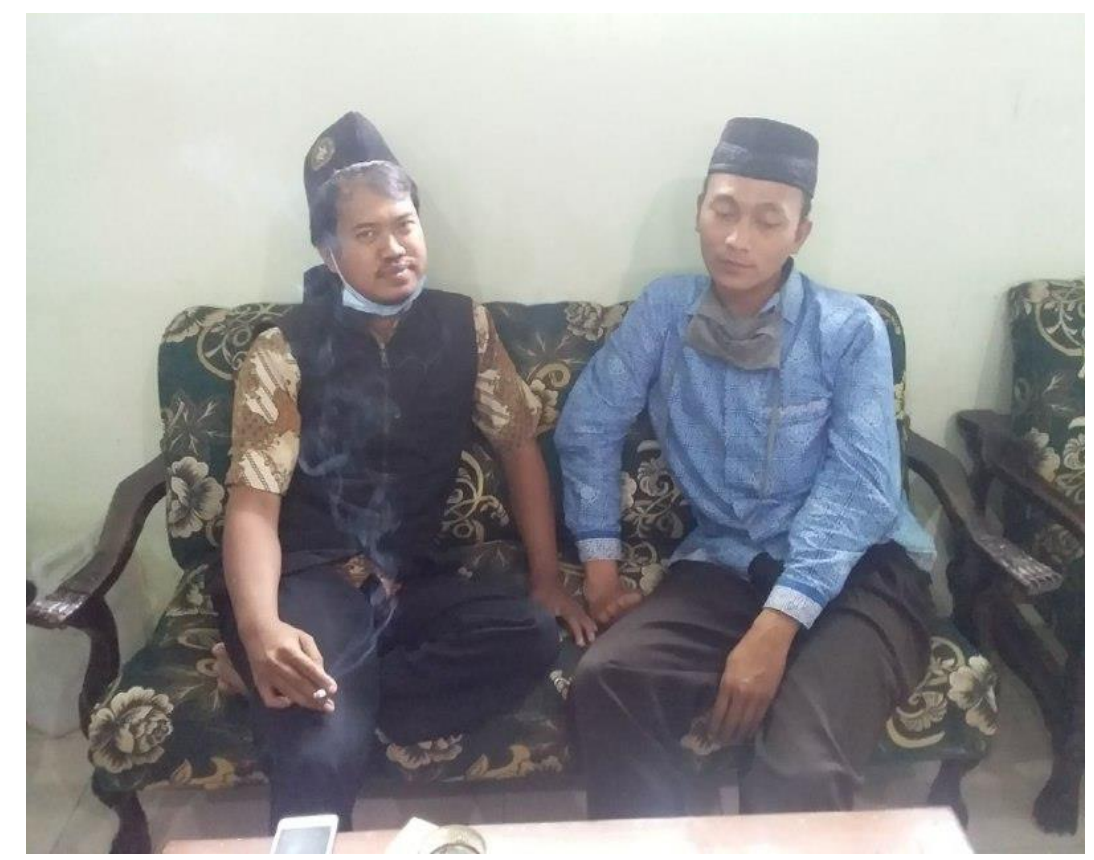

Gambar 2. Proses Mendengarkan Pelanggan

Hasil dari mendengarkan pelanggan antara lain:

a. Pihak SMP NJ Membutuhkan Sistem Absensi Online untuk siswa, awal mula ingin membuat sebuah sistem yang berbasis barcode, kemudian barcodenya ada pada kartu pelajar siswa, namun hal ini tidak bisa diterapkan karena siswa smpnj yang banyak, kemudian kartu pelajar rawan untuk hilang sehingga akan merepotkan jika diterapkan di SMP Nurul Jadid

b. Dari Hasil diskusi dan pembicaraan akhirnya diputuskan untuk absensi tetap dilakukan oleh guru, namun guru tidak lagi mengabsen siswa secara manual melainkan memanfaatkan bot Telegram, sehingga sistem yang nantinya merekap data secara otomatis

c. Selain perizinan hal pengting lainnya yang dibutuhkan di SMP Nurul Jadid masalah merekap data pelanggaran siswa yang mana nanti pelanggaran siswa juga akan menggunakan botTelegram untuk menginputkan datanya 


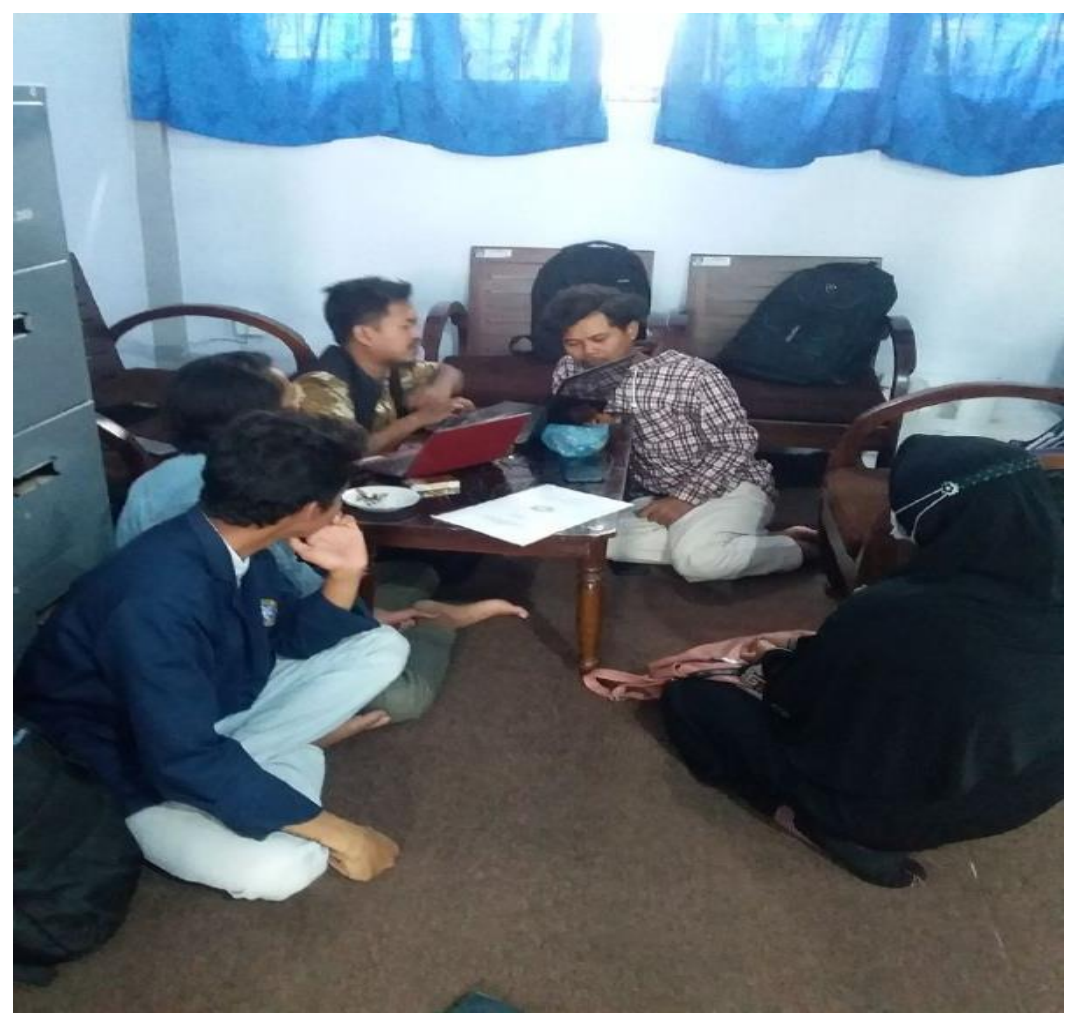

Gambar 3. Proses Membangun Sistem

Hasil dari membangun sistem pelanggan antara lain:

\section{a. Desain ERD}

b. Pembuatan Bot Telegram di Bot Father

c. Bahasa Pemograman yang digunakan Framework php yaitu Codelgniter

d. Untuk pengembangan Bot Telegram menggunakan bahasa pemograman Python

e. Aplikasi berbasis web yang terintegrasi dengan BotTelegram

Berikut ini adalah cara penggunaan bot telegram untuk mengabsen siswa siswi yang ada pada SMP Nurul Jadid:

a. Pastikan di android anda sudah terinstal aplikasi telegram

b. Masuk ke aplikasi telegram lalu ketikan "absensi smp nurul jadid"

c. Setelah itu anda bisa melakukan absensi pada siswa

d. Lalu pada bot tersebut akan ada tulisan "Mulai Ulang" seperti pada gambar di bawah ini 


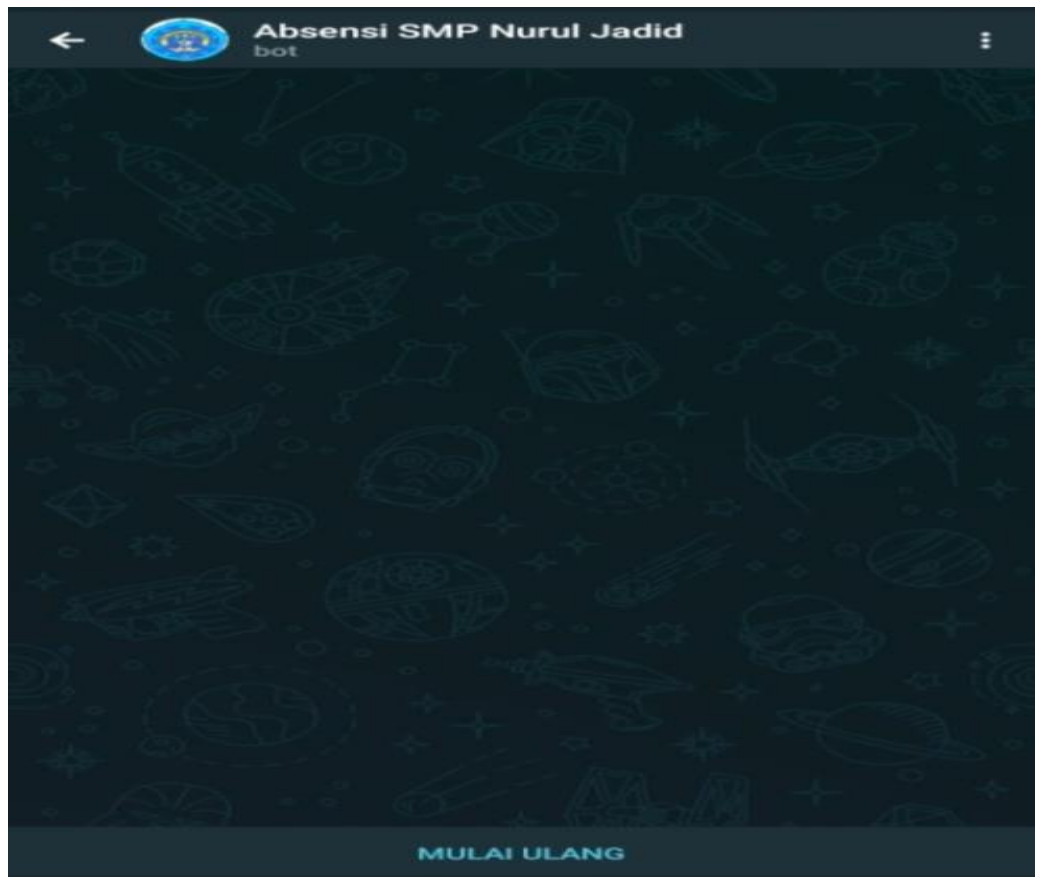

Gambar 4. Tampilan awal Bot Telegram Absensi

e. Lalu tekan "/start" pada menu

f. Pada bot tersebiut ada menu "/pilih"

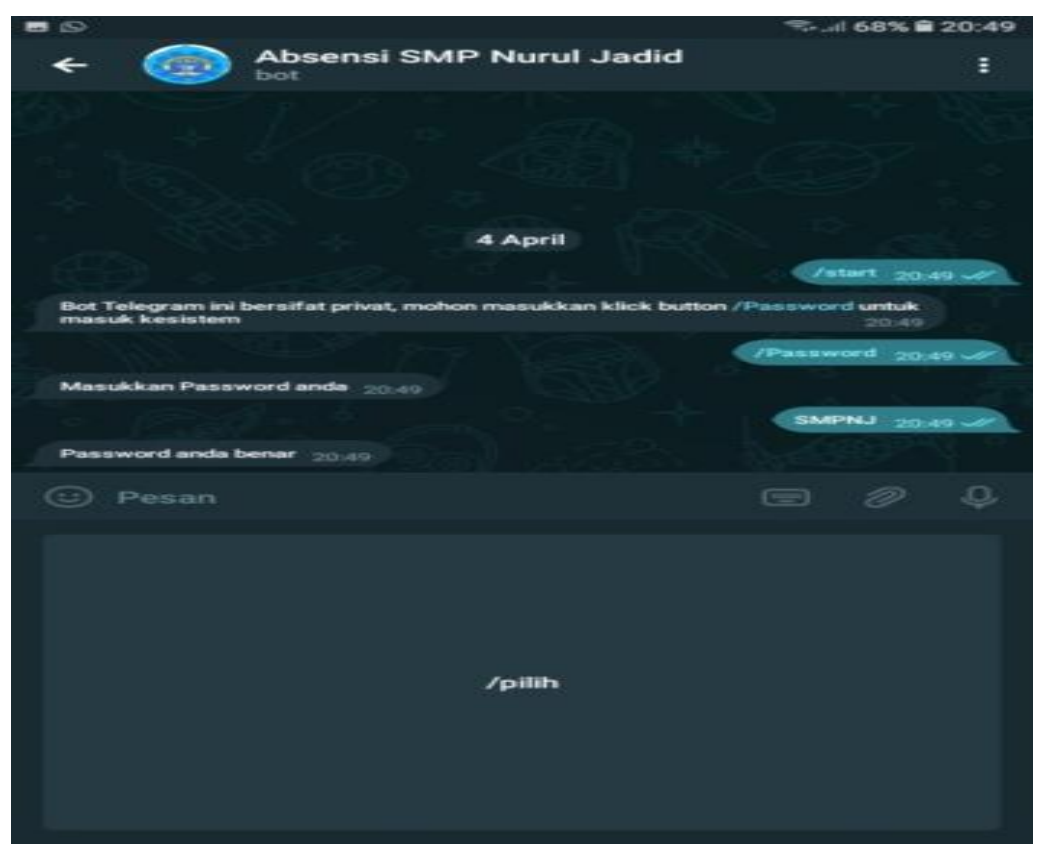

Gambar 4. BotTelegram member pilihan untuk mengabsen atau input pelanggaran siswa 


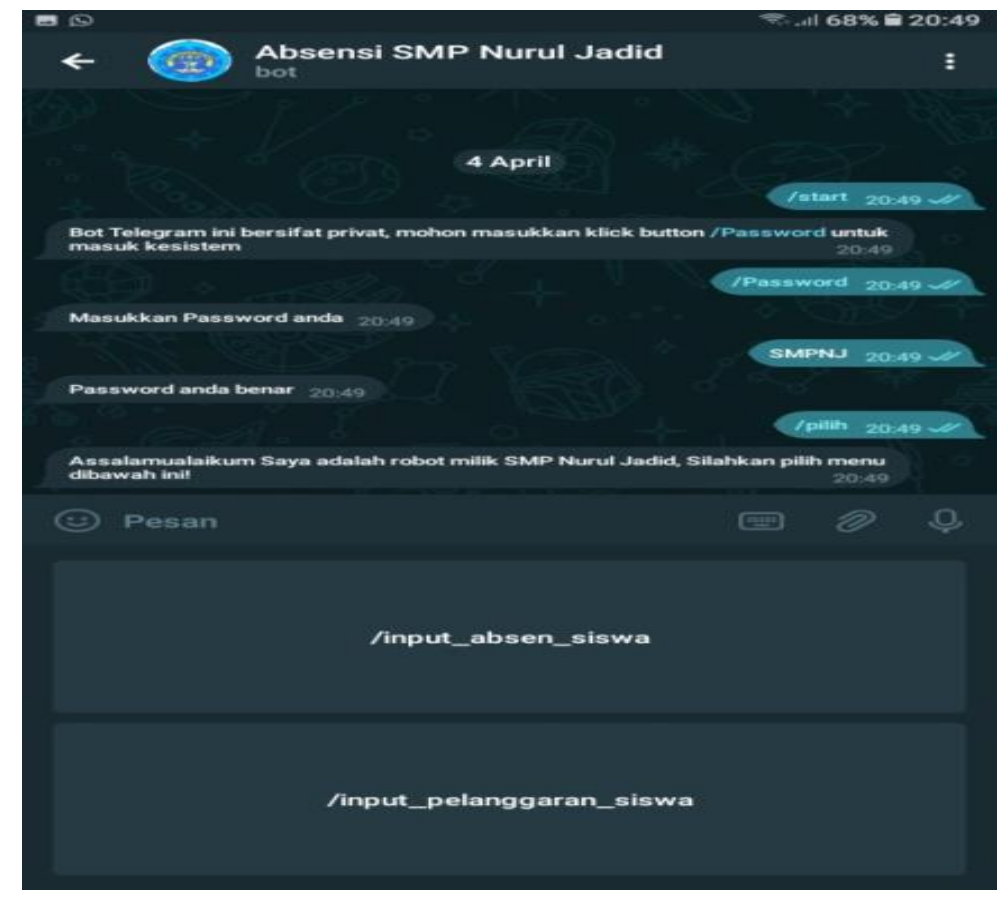

Gambar 5. customKeyboard BotTelegram akan member opsi, apakah guru akan mengabsen siswa atau menginput pelanggaran siswa

g. Lalu pilihkan kelas yang akan di absen

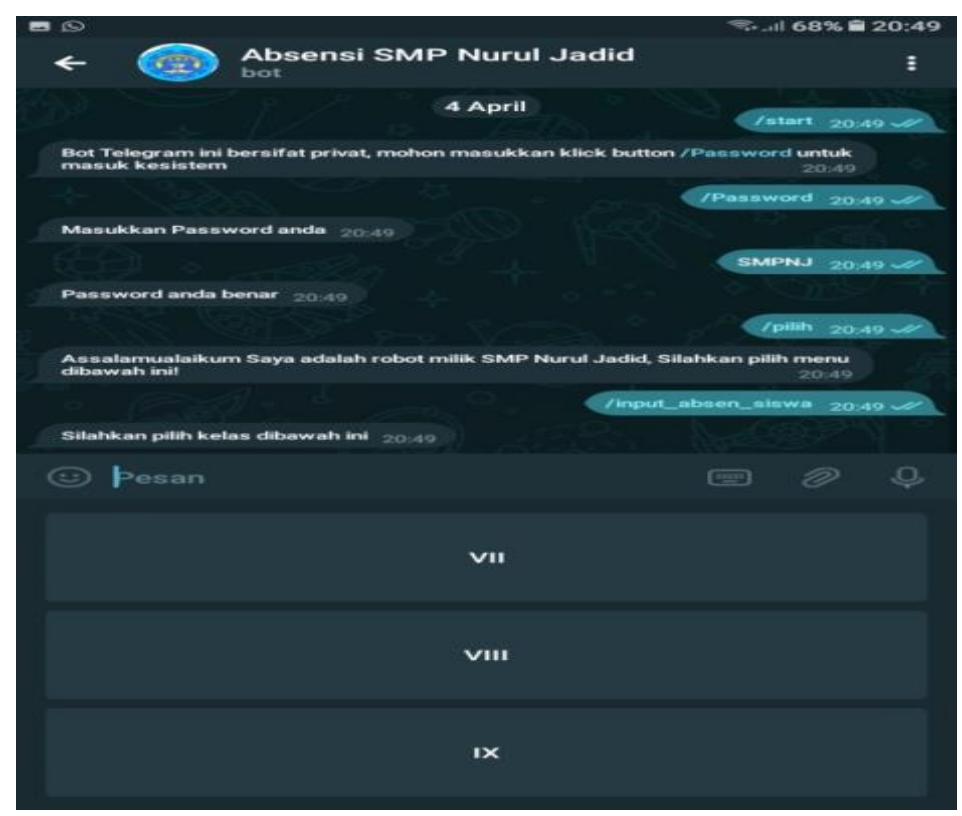

Gambar 6. CustomKeyboard BotTelegram akan member opsi untuk memilih kelas yang akan diabsen 
h. Pilih nama anda (guru) yang akan mengabsen siswa

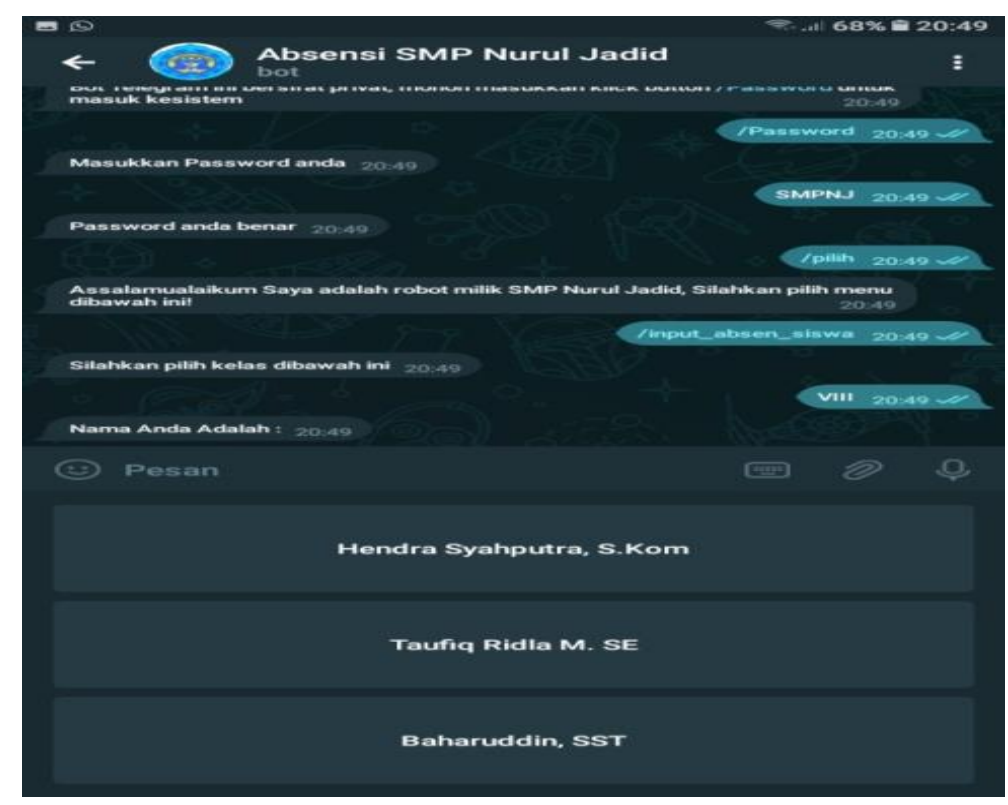

Gambar 7. customKeyboard BotTelegram akan member opsi untuk memili guru yang akan mengabsen siswa

i. pilihlah mata pelajaran anda

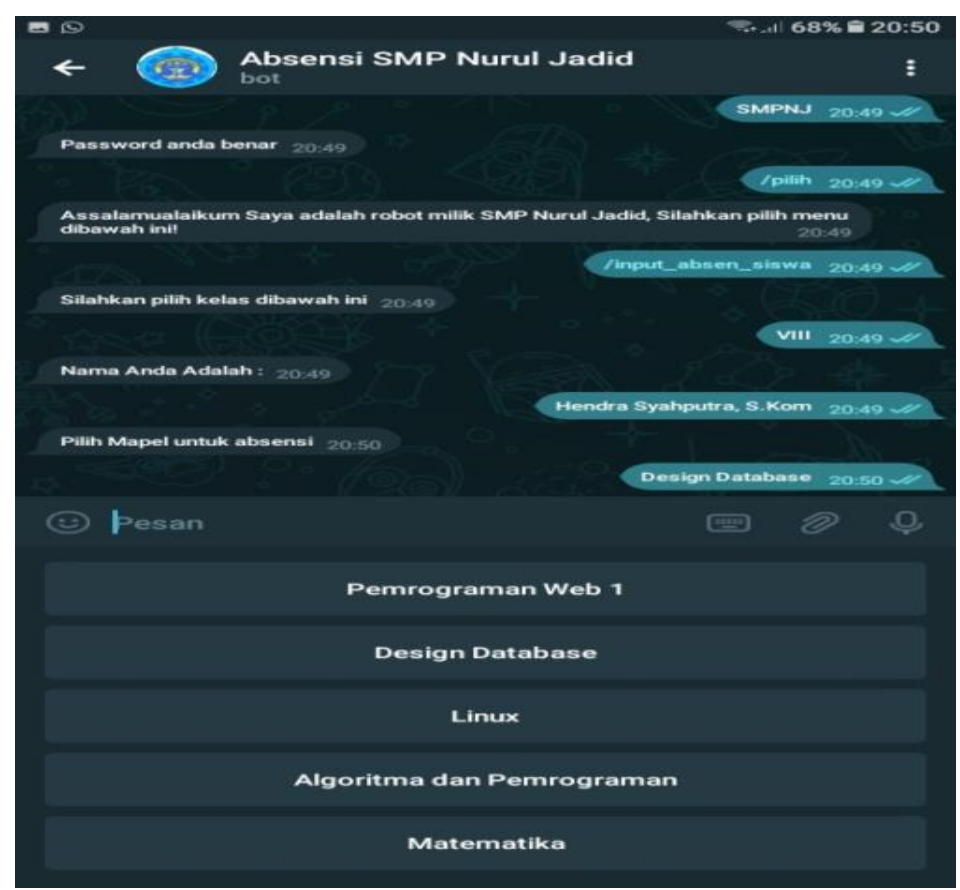

Gambar 8. customKeyboard BotTelegram akan member opsi kepada guru untuk memilih mata pelajaran 
j. setelah itu pilihlah nama siswa yang tidak masuk sekolah

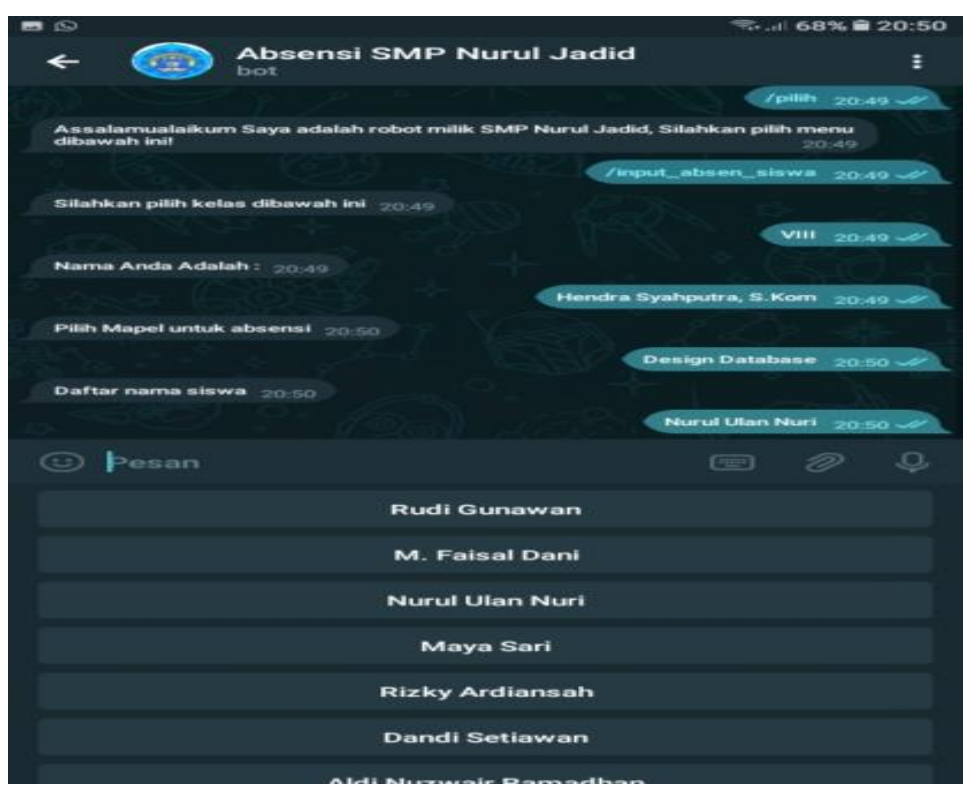

Gambar 9. customKeyboard BotTelegram akan member opsi kepada guru untuk memilih siswa yang tidak masuk kelas

k. Guru mengabsen siswa

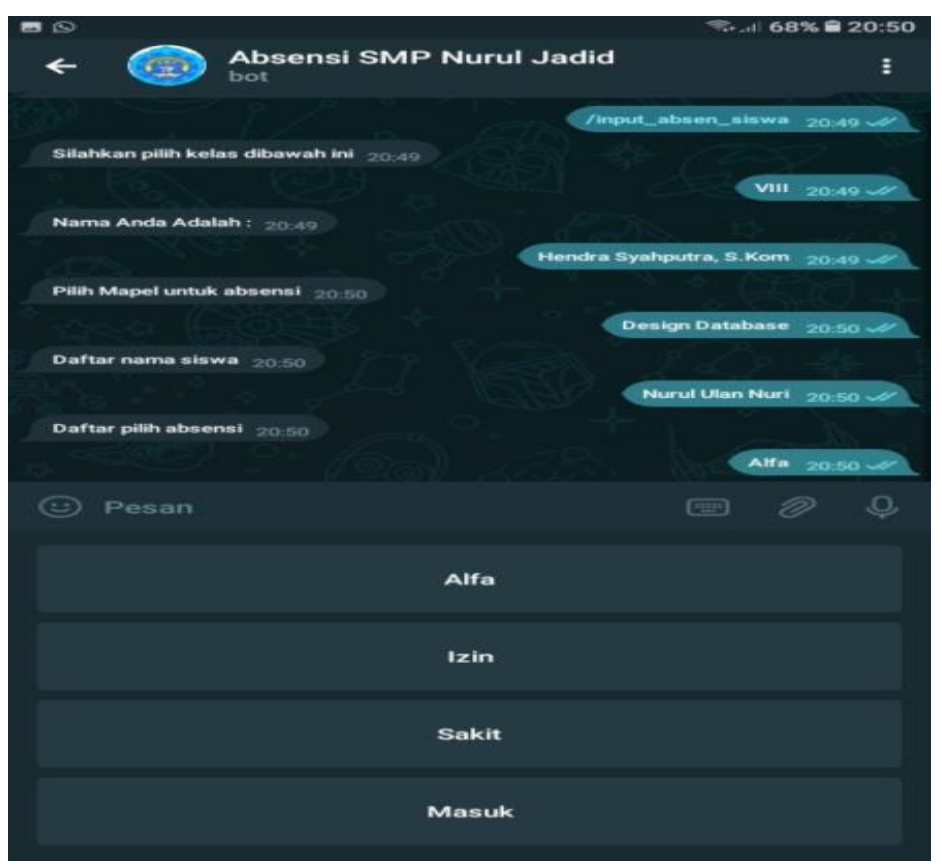

Gambar 10. CustomKeyboard BotTelegram akan member opsi kepada guru untuk memilih keterangan siswa yang tidak masuk kelas 
Berikut ini adalah tampilan ablikasi berbasis web yang menggunkan framework Codelgniter

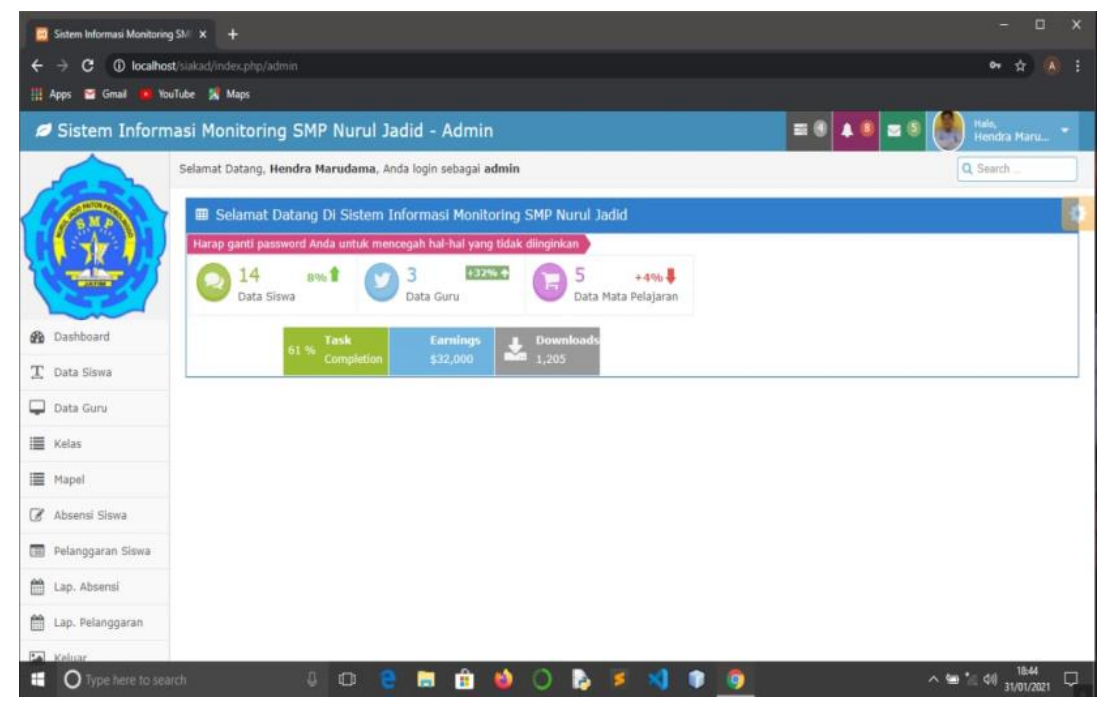

Gambar 11. Tampilan dashbor aplikasi absensi berbasis web

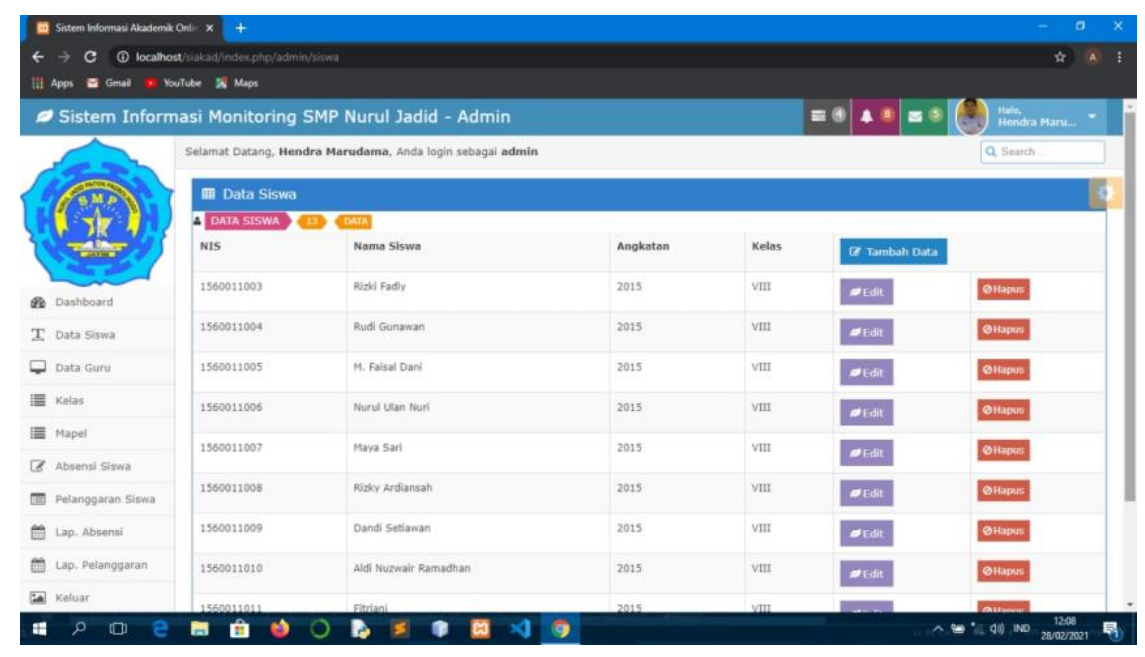

Gambar 12. Tampilan Menu Master siswa 


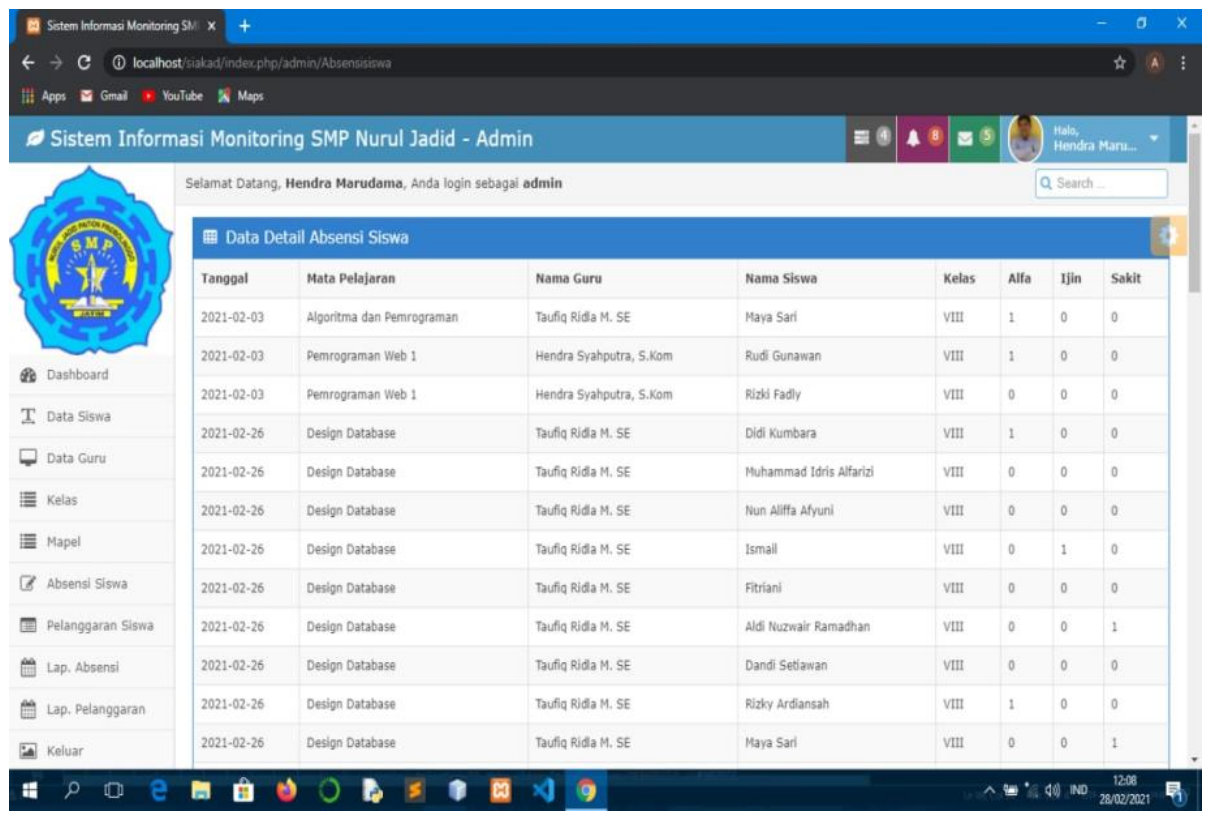

Gambar 13. Laporan Rekap Absensi Siswa

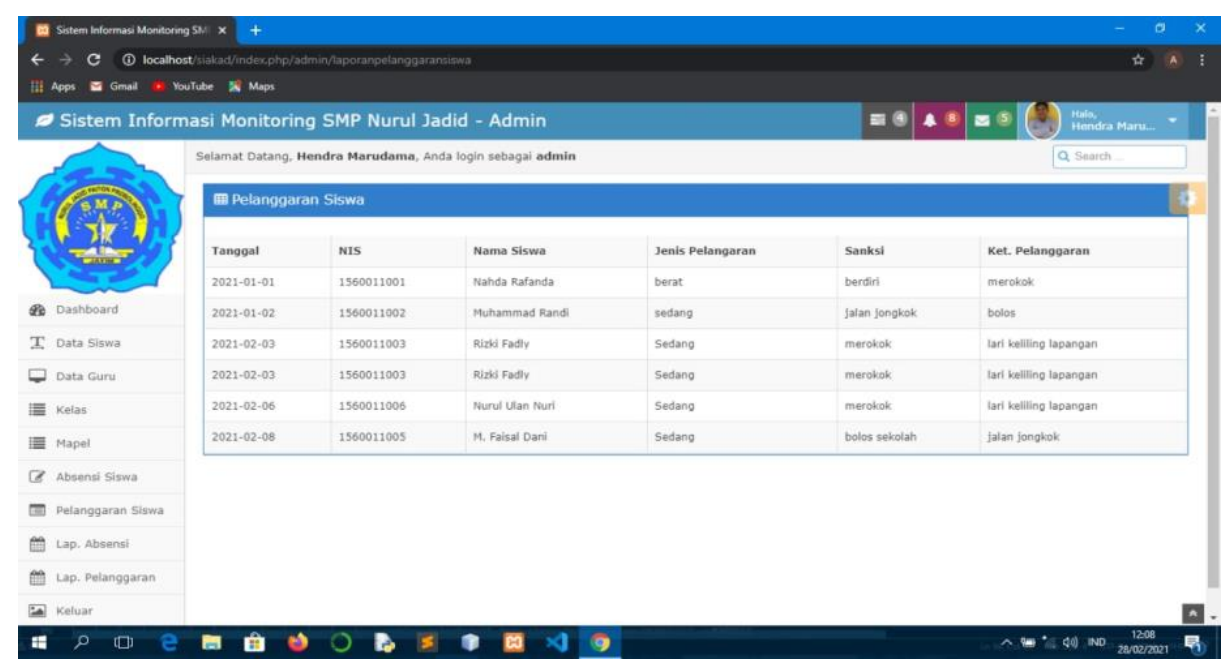

Gambar 14. Laporan Rekap Pelanggaran Siswa 


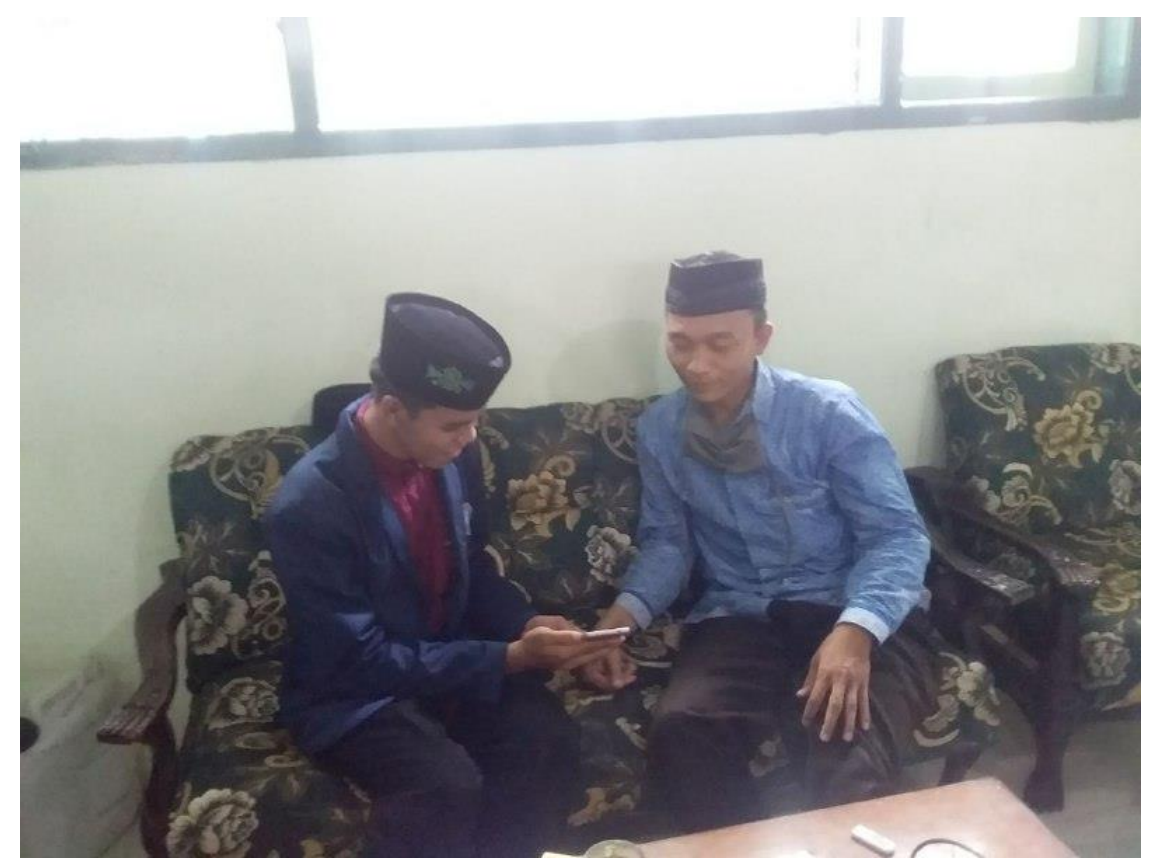

Gambar 15. Pelanggan Menguji Coba Prototype

Hasil dari membangun sistem menguji coba sistem:

a. Yang akan diabsen cukup yang tidak masuk saja, sedangkan yang masuk akan otomatis dinyatakan masuk, hal ini dimaksudkan agar pepngabsenan siswa menjadi lebih efisien dan cepat

b. Pelanggaran siswa sudah ada aplikasi excelnya sehingga pihak progremer cukup meniru sistem penginputan pelanggaran yang ada diexcel

c. Yang akan melatih guru nanti bagian kedisplinan dan kesiswaan, devoleper cukup melati bagian kedisplinan dan kesiswaan yang ada pada SMP Nurul Jadid

\section{Kesimpulan}

Adapun kesimpulan dari penelitian terkait pendampingan metode prototype adalah sebagai berikut ini:

a. Dengan menggunakan prototyping terciptakomunikasi yang baik antara developer dan user.

b. Developer bisa bekerja lebih terarah dalam menentukan kebutuhan user.

c. User dapat berperan aktif dalam pembuatan dan pengembangan system. 
d. Dapat menghemat waktu dalam pembuatan dan pengembangan sebuah system.

e. Dihasilkan aplikasi yang lebih powerfull karena penggunaan menjadi lebih mudah karena user mengetahui cara kerja sistem karena user ikut terlibat dalam pembuatan system.

\section{Referensi}

Fajri, FN., Malik, Kamil. Sa'diya, Halimatus. (2020). Pengembangan Sistem Informasi Monitoring Program Kerja Berbasis Android pada Fakultas Teknik Universitas Nurul Jadid. JIMP: Jurnal Informatika Merdeka Pasuruan.

Gazali, Marlina. (2013). Optimalisasi Peran Lembaga Pendidikan Untuk Mencerdaskan Bangsa. Jurnal Al-Ta'dib

Malik, Kamil., \& Faid, Mochammad. (2016). Prediksi Prestasi Siswa Smp Nurul Jadid Menggunakan Algoritma C4.5. NJCA: Nusantara Journal of Computers and its Applications.

Purnomo, Dwi. (2017). Model Prototyping Pada Pengembangan Sistem Informasi. JIMP: Jurnal Informatika Merdeka Pasuruan

smpnj.sch.id. "Sejarah SMPNJ". smpnj.sch.id/Tentang/sejarah (diakses pada 15 Maret 2021)

smpnj.sch.id."Profil SMPNJ". smpnj.sch.id/Tentang/profil (diakses pada 15 Maret 2021) 